九州大学学術情報リポジトリ

Kyushu University Institutional Repository

Correlations between hardness and atomic bond parameters of pure metals and semi-metals after processing by high-pressure torsion

Edalati, Kaveh

Department of Materials Science and Engineering, Faculty of Engineering, Kyushu University

Horita, Zenj i

Department of Materials Science and Engineering, Faculty of Engineering, Kyushu University

http://hdl. handle. net/2324/25495

出版情報：Scripta Materialia. 64（2)，pp.161-164，2011-01. Elsevier バージョン :

権利関係 : (C) 2010 Acta Materialia Inc. 
Scripta Materialia 64 (2011) 161-164

Received 17 August 2010; revised 11 September 2010; accepted 17 September 2010

Available online 25 September 2010

\section{Correlations between hardness and atomic bond parameters of pure metals and semi-metals after processing by high-pressure torsion}

Kaveh Edalati* and Zenji Horita

Department of Materials Science and Engineering, Faculty of Engineering, Kyushu University, Fukuoka 819-0395, Japan

High-purity elements (magnesium, aluminum, silicon, scandium, titanium, vanadium, chromium, manganese, iron, cobalt, nickel, copper, zinc, germanium, zirconium, niobium, molybdenum, palladium, silver, indium, tin, tellurium, neodymium, hafnium, tantalum, tungsten, rhenium, platinum, gold and lead) were processed by high-pressure torsion and subsequently evaluated by Vickers microhardness measurements. The hardness at the steady state was expressed as a unique function of atomic bond energy, specific heat capacity, specific latent heat of fusion, linear thermal expansion coefficient and activation energy for self-diffusion.

Keywords: High-pressure torsion; Ultrafine-grained microstructure; Severe plastic deformation; Hardness

*Corresponding author. Tel./fax: +81 92802 2992;

e-mail: kaveh.edalati@zaiko6.zaiko.kyushu-u.ac.jp 
Ultrafine-grained microstructures, high strength and reasonable ductility are successfully attained in bulk pure metals through the application of high-pressure torsion (HPT). The HPT method, which was first introduced by Bridgman in 1935 [1], has been applied to a wide range of body-centered cubic (bcc) metals such as Fe [2], V [3], Nb [4], Cr [5], Mo [6] and W [7], face centered cubic (fcc) metals such as $\mathrm{Al}$ [8], $\mathrm{Cu}$ [9], $\mathrm{Ag}$ [10], $\mathrm{Au}$ [10], Ni [11], Pt [12] and Pd [13], hexagonal close-packed (hcp) metals such as Mg [14], Ti [15], Zr [16], Hf [17] and Co [18], and semi-metals with a diamond cubic structure such as Si [19] and Ge [20]. Earlier reports showed that the hardness variation is represented by a unique function of the equivalent strain in Fe [21], $\mathrm{V}$ [3], Mo [3], Al [22-24], Cu [25], Ag [12], Au [12], Ni [12], Pt [12], Ti [26], Zr [27] and Hf [17]. For all pure metals, the hardness saturates to steady-state levels at high strains where the hardness remains unchanged with further straining. It was shown that for each metal the steady-state levels are reasonably the same irrespective of the pressure of the initial state of materials before processing and of HPT processing using a disc shape [28], a ring shape $[12,21,25]$ and a sheet shape [29].

The mechanism for the occurrence of a steady state can be attributed to a balance between the energy increase through strain-induced processes such as vacancy production, dislocation accumulation and grain refinement and energy reduction through thermal processes such as self-diffusion, recovery and recrystallization. All these phenomena are influenced by atomic bond energy, and thus it is anticipated that the hardness at the steady state depends upon the atomic bond parameters. To the best of the authors' knowledge, little is understood to date regarding the correlations between the hardness and the atomic bond parameters of pure metals after processing with HPT. Buch [30,31] reported some relations between the mechanical properties and the atomic bond parameters of pure metals deformed by conventional processes. Since the mechanical properties of pure metals are influenced by processing parameters such as imposed strain and heating hysteresis and by microstructural features such as grain size, dislocation density and texture, it is not easy to establish correlations between the mechanical properties and the atomic bond parameters at non-steady-state conditions. However, the mechanical properties saturate to steady-state levels by processing through HPT and the mechanical properties at the saturation are less sensitive to the processing parameters [12,28,29]. Therefore, HPTprocessed pure metals are ideal candidates with which to investigate the relations between mechanical properties and atomic bond parameters.

In the present investigation, and for the first time, 30 high-purity elements are processed by HPT and the correlations between the hardness and the atomic bond energy, and related parameters such as specific heat capacity, specific latent heat of fusion, linear thermal expansion coefficient and activation energy for self-diffusion, are investigated.

Thirty pure metals and semi-metals with different crystal structures were investigated in this study. The purity levels were 99\% for Ta and W and 99.9\% or higher for the other elements. For each metal, the atomic bond energy $\Delta H$, specific heat capacity $Q$, latent heat of fusion $L$, linear thermal expansion coefficient at room temperature $\alpha$ and activation energy for self-diffusion $Q_{S D}$ are given in Table 1. The presented data were taken from Refs. [30-35].

The as-received specimens were cut into discs $10 \mathrm{~mm}$ in diameter and $0.8 \mathrm{~mm}$ in thickness using a wire-cutting electric discharge machine. HPT was carried out on the discs at room temperature using the facilities described previously [21,27]. The disc samples were processed under a selected pressure in the range of $P=2-6 \mathrm{GPa}$ for $N=4-10$ revolutions with a rotation speed of $\omega=0.2-1 \mathrm{rpm}$. For Ti and Zr, the HPT was conducted under a pressure of $2 \mathrm{GPa}$, which 
is smaller than the critical pressure for $\omega$-phase formation [26,27]. The samples after HPT were kept at room temperature for $30 \mathrm{~h}$. Thereafter, the samples were polished to a mirror-like finish and the Vickers microhardness was measured from the center to the edge in eight different radial directions. The average was taken from eight measurements at equal distances from the disc center. The average values were then plotted against the distance from the center, as done previously $[17,21,22,25]$. The hardness in this study was taken from the hardness level at the steady state, where the hardness remained unchanged with distance from the disc center.

Microhardness values at the steady state are plotted in Figure 1 against (a) the atomic number $(Z)$ and (b) the atomic bond energy $(\Delta H)$. Here, $\Delta H$ is the enthalpy required to break all atomic bonds in one cubic meter of pure element [32]. Figure 1a shows that the hardness tends to increase with increasing $Z$ for groups IVB (Ti, Zr, Hf), VB (V, Nb and Ta), VIB (Cr, Mo, W) and VIIB (Mn, Re). The hardness tends to decrease with increasing Z for groups VIIIB (Ni, Pd, Pt), IB $(\mathrm{Cu}, \mathrm{Ag}, \mathrm{Au})$, IIIA ( $\mathrm{Al}, \mathrm{In})$ and IVA ( $\mathrm{Si}, \mathrm{Ge}, \mathrm{Sn}, \mathrm{Pb})$. However, it appears that there is no specific rule governing the relation between the hardness and $Z$ except that the first four groups consist of elements having the hcp and bcc crystal structures, the next two groups have an fcc crystal structure and the last two groups are mainly of diamond and tetragonal structures. Alternatively, when the hardness is plotted against $\Delta H$, as in Figure $1 \mathrm{~b}$, it is apparent that there is a good correlation between the two parameters, with the hardness increasing with increasing $\Delta H$. The relations held for the eight groups now exhibit positive slopes which reasonably follow a general correlation between the hardness and $\Delta H$. This correlation arises because of the following reason. The indenter forces the inter-atomic lengths to expand or compress, but the inter-atomic forces and energies oppose the external force. Once the external force exceeds a critical value for each atomic bond, the bond will break and the material will start to deform plastically. Therefore, the materials with higher $\Delta H$ exhibit higher hardness. The trend in Figure $1 \mathrm{~b}$ suggests that there should be a correlation between the hardness at the steady state and physical parameters related to $\Delta H$. In the following, we examine the correlations between the hardness and four well-known atomic bond parameters: the specific heat capacity $(Q)$, the specific latent heat of fusion $(L)$, the linear thermal expansion coefficient $(\alpha)$ and the activation energy for self-diffusion $\left(Q_{S D}\right)$.

Figure 2 shows the variation in the hardness at the steady state with respect to (a) $Q$ and (b) $L$. Here, $Q$ represents the maximum energy that can be stored in a unit volume before it melts and $L$ represents the energy required for melting a unit volume of material at the melting temperature. It is apparent that the hardness values are represented well as a unique function of $Q$ in Figure 2a. The hardness increases monotonically with increasing $Q$ except for $\mathrm{Si}$ and $\mathrm{Ge}$, which are classified as semi-metals having strong covalent bonds. It is known that $\mathrm{Si}$ and Ge partly transform to an amorphous state during indentation [36], thus it should be difficult to measure their real hardness. Inspection of Figure 2b shows that the hardness increases as a function of $L$. The correlation between the hardness and $L$ is not as good as that between the hardness and $Q$. However, the data points for $\mathrm{Si}$ and Ge are now closer to the fitted curve in Figure $2 \mathrm{~b}$ than in Figure 2a. Since $Q$ and $L$ increase with increasing $\Delta H$, the correlations indirectly indicate that the hardness level at the steady state depends upon $\Delta H$ and thus the energy required for breaking atomic bonds for plastic deformation.

Figure 3 plots the hardness at the steady state as a function of $\alpha$ for the 30 elements covered in this study. The hardness decreases as a hyperbolic function of $\alpha$. For Mn, Si and Ge, the data points deviate significantly from the fitted curve when compared to the other elements. Because a higher value of $\alpha$ is related to a weaker inter-atomic bond, it is reasonable that the hardness level is lowered with increasing $\alpha$. 
The hardness at the steady state is plotted in Figure 4 against $Q_{S D}$. The hardness increases with increasing $Q_{S D}$ and all the data points lie well on a single curve except for $\mathrm{Ti}, \mathrm{Zr}$ and $\mathrm{Hf}$ in group IVB and $\mathrm{Nb}$ in group VB. The correlation shown in Figure 4 can be attributed to the fact that the thermal recovery, which is a crucial factor for reaching a steady state, is related to $Q_{S D}$ : the higher the $Q_{S D}$, the smaller the recovery and thus the more enhanced the hardness. It is noted that $\mathrm{Ti}, \mathrm{Zr}$ and $\mathrm{Hf}$ were also exceptions to the universal level determined by shear modulus compensated by homologous temperatures as reported in an earlier paper [12]. It is reasonable to consider that $Q_{S D}$ is strongly influenced by $\Delta H$ because one atom needs to break bonds with neighboring atoms and moves to an adjacent site. Therefore, for elements with higher $\Delta H$, more energy is required to overcome the barriers for diffusion, and thus they exhibit a higher hardness. In summary, all plots clearly demonstrate that there exist good correlations between the hardness at the steady state established after processing by HPT and $\Delta H$ and related parameters such as $Q$, $L, \alpha$ and $Q_{S D}$. The correlations hold in many pure elements irrespective of the atomic numbers, crystal structures and melting temperatures, with only minor exceptions.

Thirty metals and semi-metals, with different crystal structures (bcc, fcc, hcp, diamond cubic, complex cubic, primitive hexagonal and tetragonal), were processed by high-pressure torsion and subsequently evaluated by Vickers microhardness measurements. The hardness at the steady state after processing with HPT correlated well with the atomic bond energy $(\Delta H)$ and related parameters such as the specific heat capacity $(Q)$, the specific latent heat of fusion $(L)$, the linear thermal expansion coefficient $(\alpha)$ and the activation energy for self-diffusion $\left(Q_{S D}\right)$.

K.E. would like to thank the Islamic Development Bank for a scholarship. This work was supported in part by the Light Metals Educational Foundation of Japan, in part by a Grant-in-Aid for Scientific Research from the MEXT, Japan, in Priority Areas "Bulk Nanostructured Metals" and in part by Kyushu University Interdisciplinary Programs in Education and Projects in Research Development (P\&P).

[1] P.W. Bridgman, Phys. Rev. 48 (1935) 825-847.

[2] R.Z. Valiev, Y.V. Ivanisenko, E.F. Rauch, B. Baudelet, Acta Mater. 44 (1996) 4705-4712.

[3] E.N. Popova, V.V. Popov, E.P. Romanov, V.P. Pilyugin, Phys. Met. Metall. 101 (2006) 52-57.

[4] R. Wadsack, R. Pippan, B. Schedler, Fusion Eng. Des. 66-68 (2003) 265-269.

[5] S.W. Lee, K. Edalati, Z. Horita, Mater. Trans. 51 (2010) 1072-1079.

[6] Y.R. Kolobov, B. Kieback, K.V. Ivanov, T. Weissgaerber, N.V. Girsova, Y.I. Pochivalov, G.P. Grabovetskaya,

M.B. Ivanov, V.U. Kazyhanov, I.V. Alexandrov, Int. J. Refract. Met. Hard Mater. 21 (2003) 69-73.

[7] Q. Wei, H.T. Zhang, B.E. Schuster, K.T. Ramesh, R.Z. Valiev, L.J. Kecskes, R.J. Dowding, L. Magness, K. Cho, Acta Mater. 54 (2006) 4079-4089.

[8] C. Xu, Z. Horita, T.G. Langdon, Acta Mater. 55 (2007) 203-212.

[9] T. Hebesberger, H.P. Stuwe, A. Vorhauer, F. Wetscher, R. Pippan, Acta Mater. 53 (2005) 393-402.

[10] H. Matsunaga, Z. Horita, Mater. Trans. 50 (2009) 1633-1637.

[11] A.P. Zhilyaev, S. Lee, G.V. Nurislamova, R.Z. Valiev, T.G. Langdon, Scripta Mater. 44 (2001) 2753-2758. 
[12] K. Edalati, Z. Horita, Mater. Trans. 51 (2010) 1051-1054.

[13] Y. Ivanisenko, L. Kurmanaeva, J. Weissmueller, K. Yang, J. Markmann, H. Rosner, T. Scherer, H.J. Fecht, Acta Mater. 57 (2009) 3391-3401.

[14] B.J. Bonarski, E. Schafler, B. Milkulowskei, M.J. Zehetbauer, Mater. Sci. Forum 584-586 (2008) 263-268.

[15] A.V. Sergueeva, V.V. Stolyarov, R.V. Valiev, A.K. Mukhrjee, Scripta Mater. 45 (2001) 747-752.

[16] M.T. Perez-Prado, A.A. Gimazov, O.A. Ruano, M.E. Kassnerc, A.P. Zhilyaev, Scripta Mater. 58 (2008) 219-222.

[17] K. Edalati, Z. Horita, Y. Mine, Mater. Sci. Eng. A 527 (2010) 2136-2141.

[18] K.Y. Mulyukov, G.F. Korznikova, R.Z. Valiev, Phys. Stat. Sol. A 125 (1991) 609-614.

[19] R.K. Islamgaliev, R. Kuzel, E.D. Obraztsova, J. Burianek, F. Chmelik, R.Z. Valiev, Mater. Sci. Eng. A 249 (1998) 152-157.

[20] R.K. Islamgaliev, R. Kuzel, S.N. Mikov, A.V. Igo, J. Burianek, F. Chmelik, R.Z. Valiev, Mater. Sci. Eng. A 266 (1998) 205-210.

[21] K. Edalati, T. Fujioka, Z. Horita, Mater. Trans. 50 (2009) 44-50.

[22] Y. Harai, Y. Ito, Z. Horita, Scripta Mater. 58 (2008) 469-472.

[23] K. Edalati, Y. Ito, K. Suehiro, Z. Horita, Int. J. Mater. Res. 100 (2009) 1668-1673.

[24] K. Edalati, Z. Horita, Mater. Trans. 50 (2009) 92-95.

[25] K. Edalati, T. Fujioka, Z. Horita, Mater. Sci. Eng. A 497 (2008) 168-173.

[26] K. Edalati, E. Matsubara, Z. Horita, Metall. Mater. Trans. A 40 (2009) 2079-2086.

[27] K. Edalati, Z. Horita, S. Yagi, E. Matsubara, Mater. Sci. Eng. A 523 (2009) 277-281.

[28] F. Wetscher, A. Vorhauer, R. Pippan, Mater. Sci. Eng. A 410-411 (2005) 213-216.

[29] K. Edalati, Z. Horita, J. Mater. Sci. 45 (2010) 4578-4582.

[30] A. Buch, Pure Metals Properties, A Scientific-Technical Handbook. Metals Park, OH: ASM International/London: Freund Publishing House, 1999.

[31] A. Buch, Short Handbook of Metal Elements Properties and Elastic Properties of Pure Metals, third ed., Krzysztof Biesaga, Warsaw, 2005.

[32] J. Emsley, The Elements, second ed., Clarendon Press, Oxford, 1991.

[33] Metals Handbook, Properties and Selection of Nonferrous Alloys and Special-Purpose Materials, vol. 2, ASM International, Metals Park, OH, 1990.

[34] H. Mehrer, Diffusion in Solid Metals and Alloys, Numerical Data and Functional Relationships in Science and Technology, vol. 26, Springer-Verlag, Berlin, 1990.

[35] P. Shewmon, Diffusion in Solids, second ed., The Minerals, Metals \& Materials Society, Warrendale, PA, 1989.

[36] D.R. Clarke, M.C. Kroll, P.D. Kirchnner, R.F. Cook, Phys. Rev. Lett. 60 (1988) 2156-2159. 


\section{Table Captions}

Table 1 . Atomic bond energy $\Delta H$, specific heat capacity $Q$, specific latent heat of fusion $L$, linear thermal expansion coefficient at room temperature $\alpha$ and activation energy for self-diffusion $Q_{S D}$ for various elements.

\section{Figure Captions}

Figure 1. Vickers microhardness at steady state plotted against (a) atomic number and (b) atomic bond energy.

Figure 2. Vickers microhardness at steady state plotted against (a) specific heat capacity and (b) specific latent heat of fusion.

Figure 3. Vickers microhardness at steady state plotted against linear thermal expansion coefficient.

Figure 4. Vickers microhardness at steady state plotted against activation energy for self-diffusion. 


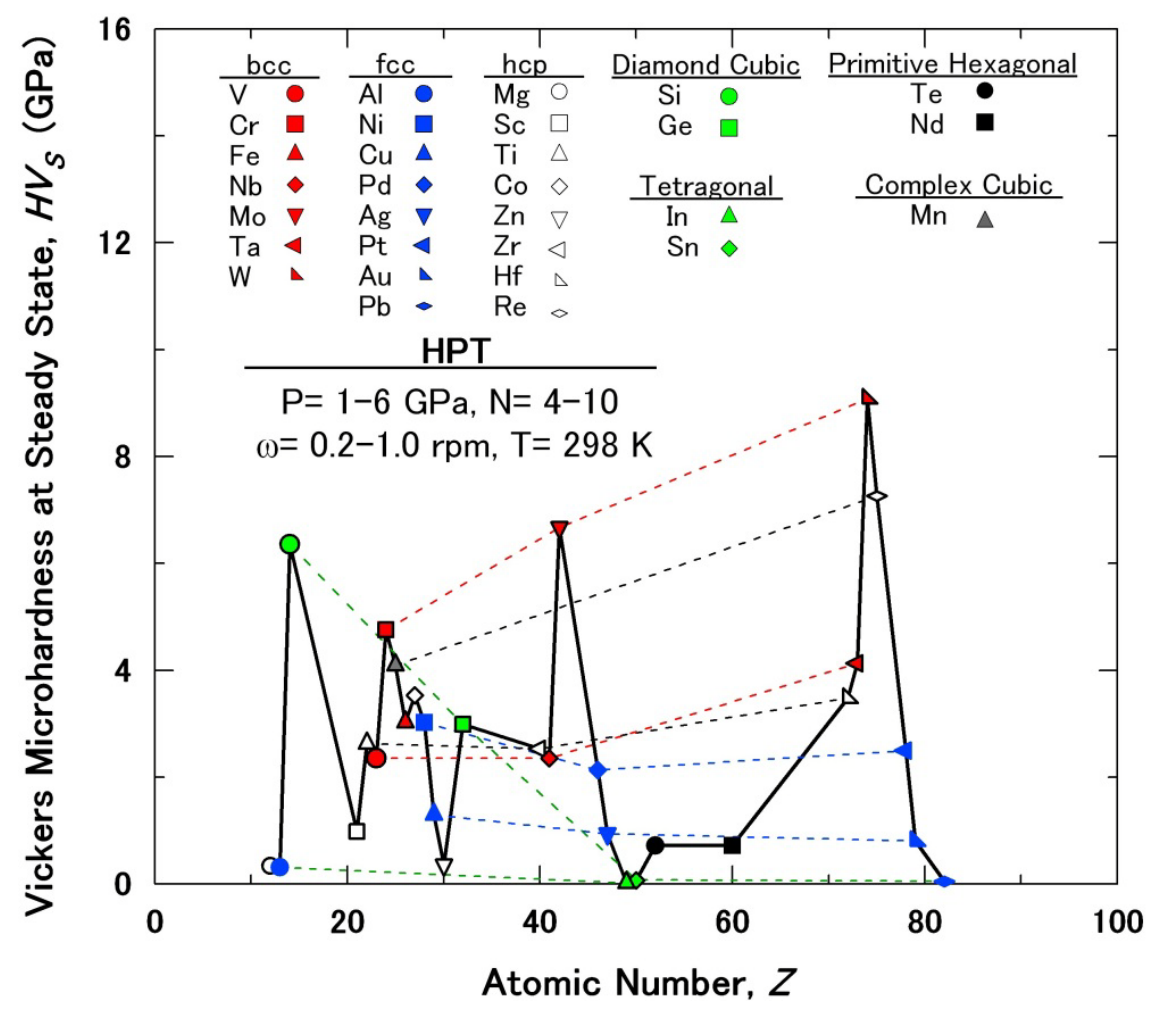

Figure 1a 


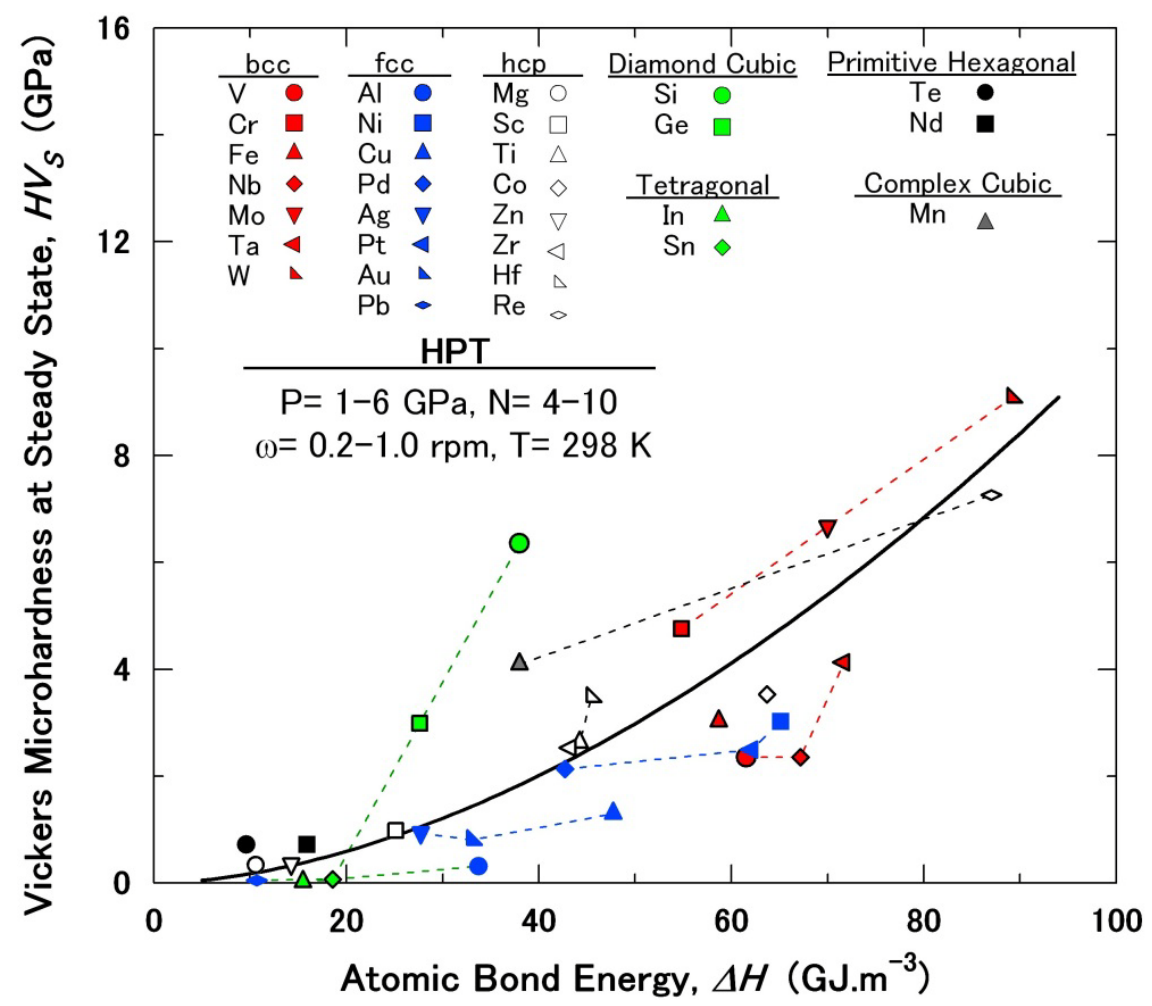

Figure 1b 


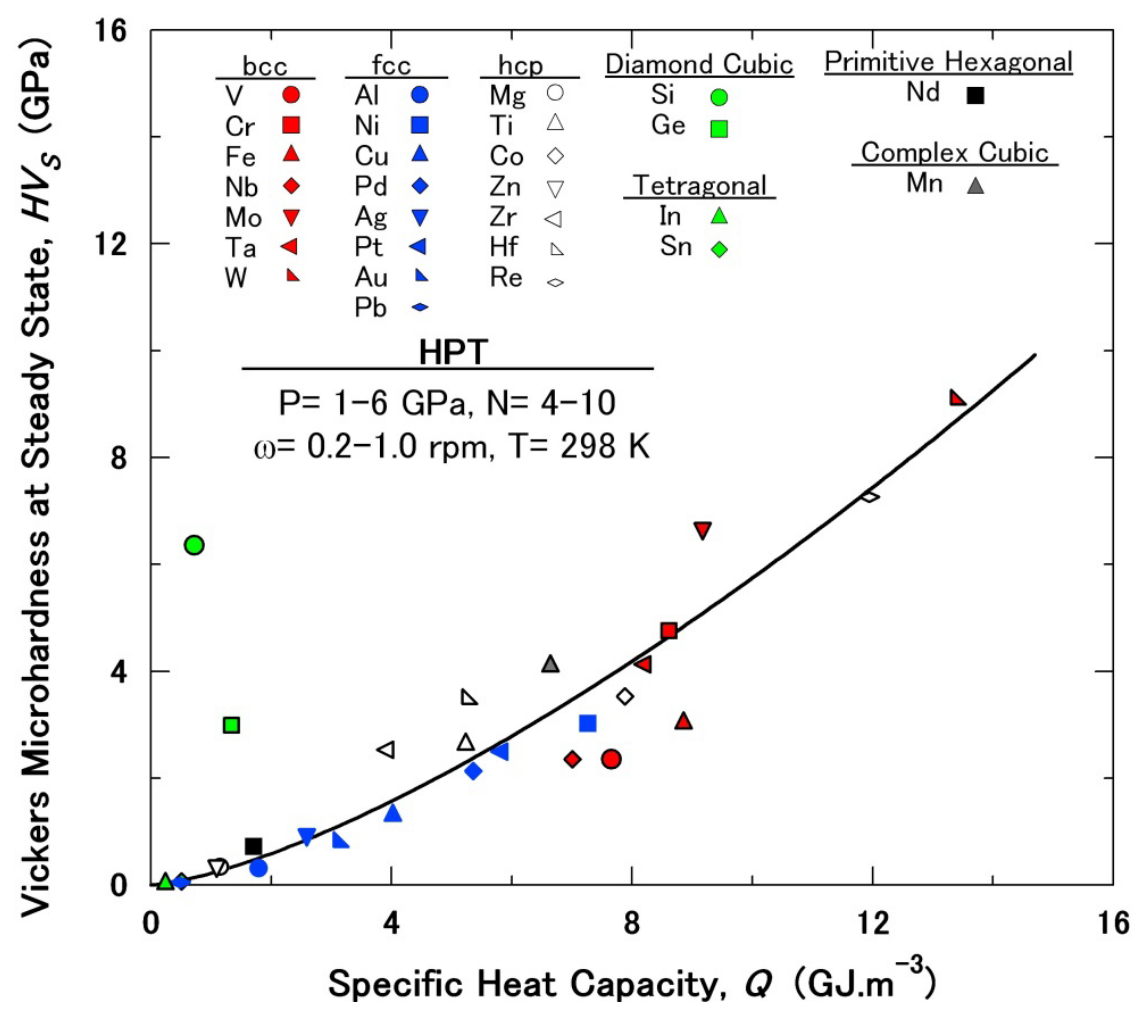

Figure 2a 


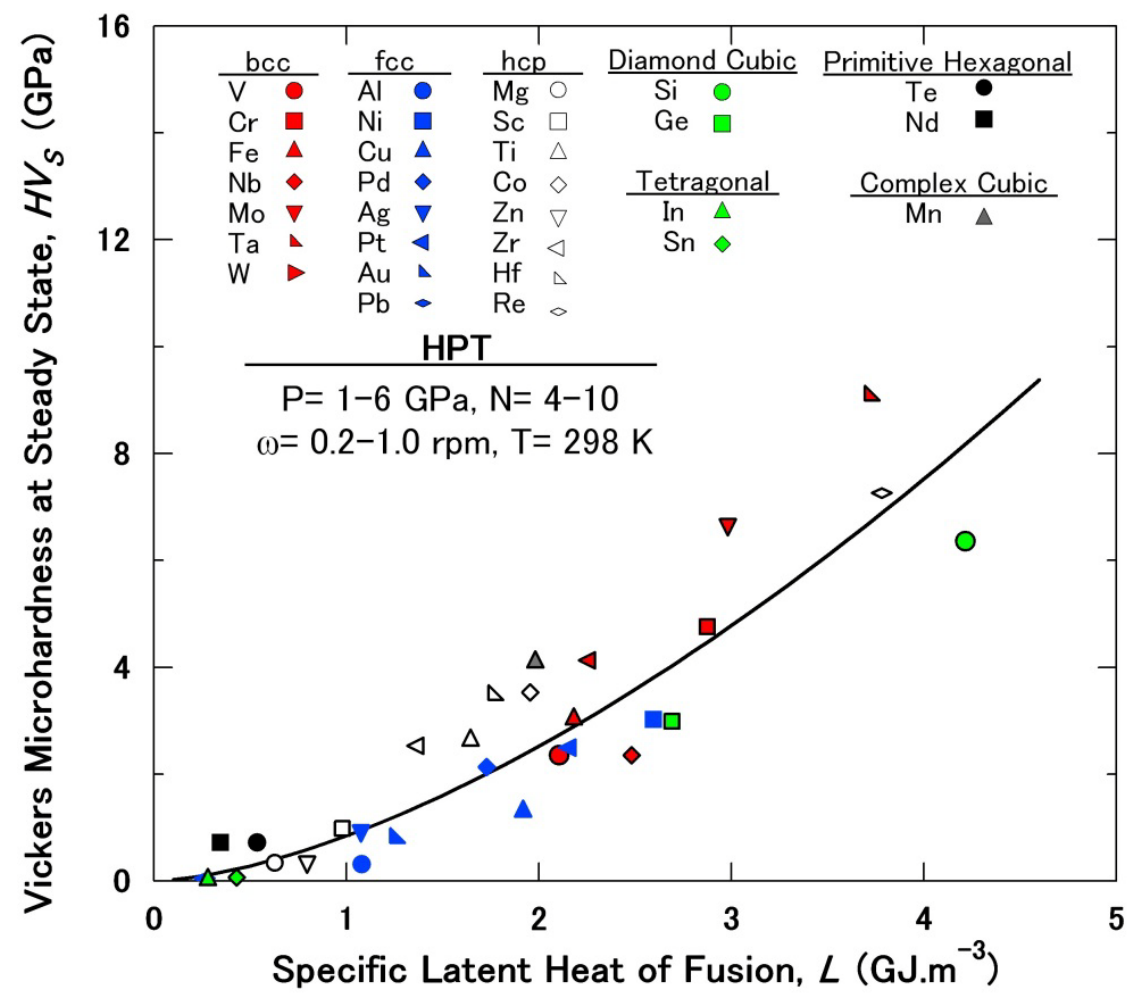

Figure 2b 


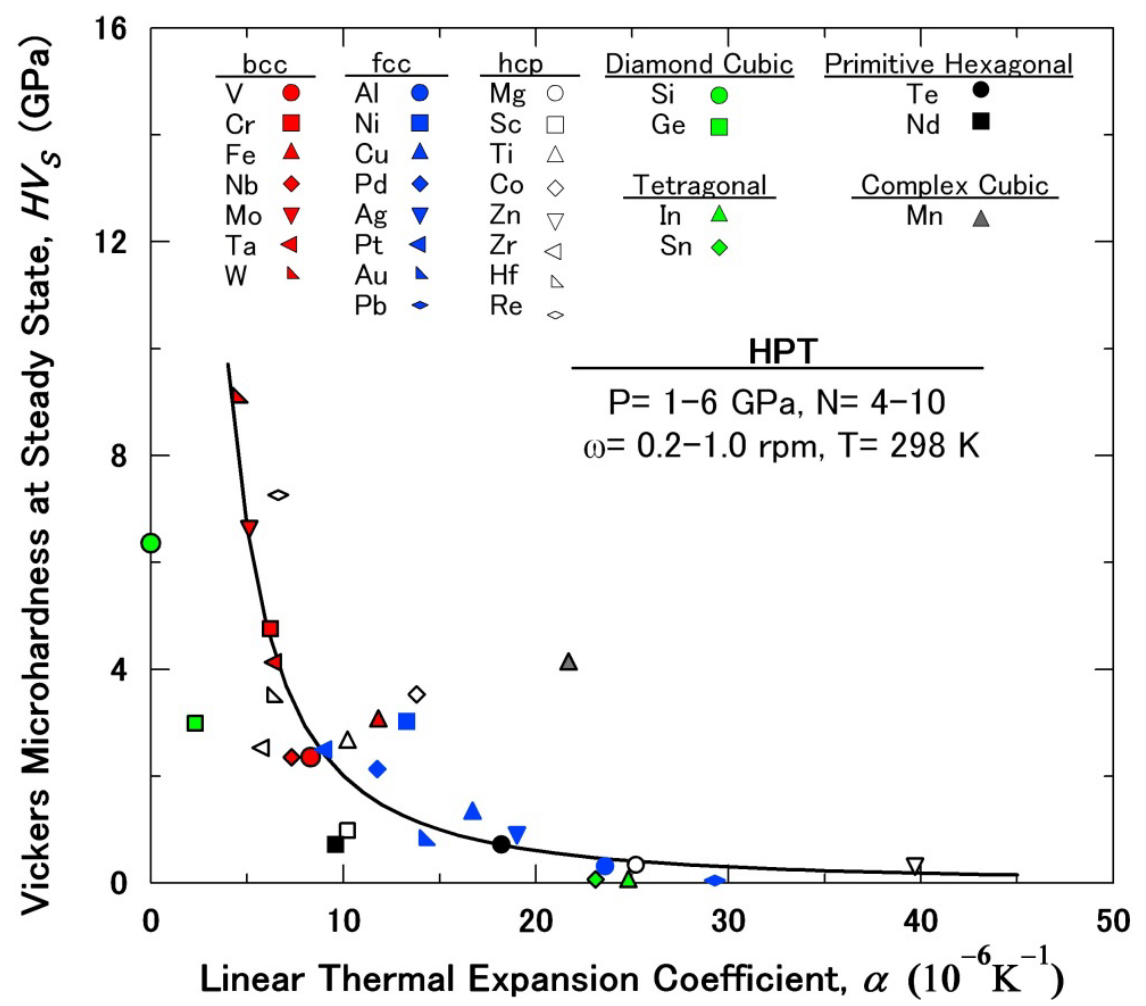

Figure 3 


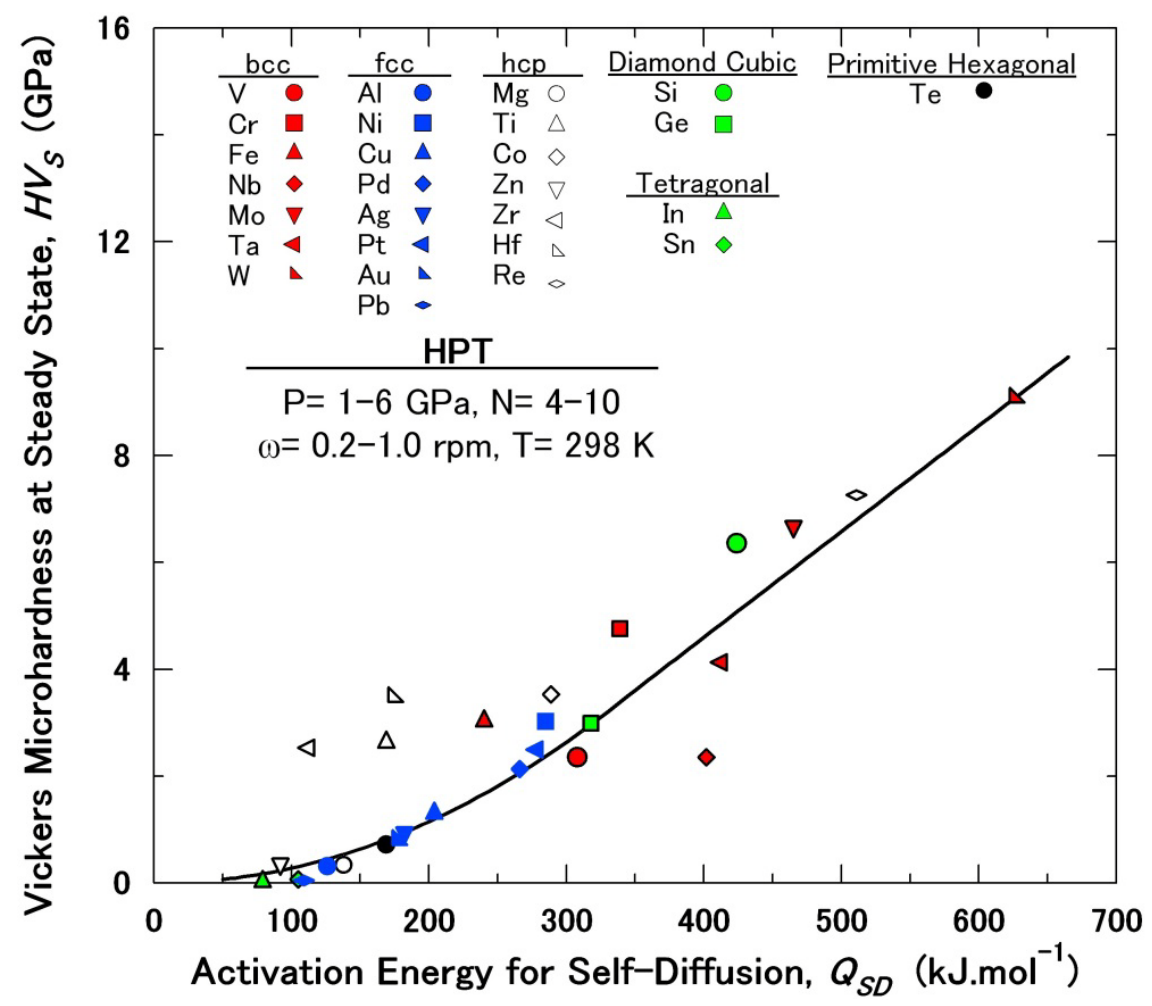

Figure 4 